\title{
Animal Agriculture, Wet Markets, and COVID-19: a Case Study in Indirect Activism
}

\author{
Alyse Spiehler ${ }^{1}$ (D) $\cdot$ Bob Fischer ${ }^{2}$ (D) \\ Accepted: 30 April 2021 / Published online: 15 May 2021 \\ (C) The Author(s), under exclusive licence to Springer Nature Switzerland AG 2021
}

\begin{abstract}
There were excellent reasons to reform intensive animal agriculture prior to COVID-19. Unfortunately, though, intensive animal agriculture has grown rapidly over the last century. All signs indicate that it will continue to grow in the future. This is bad news for billions of animals. It's also bad news for those who want an animal-friendly food system. Because the public isn't very concerned about the plight of animals - or is concerned, but has a high tolerance for cognitive dissonance - animal activists regularly engage in indirect activism. Indirect activism involves arguing that some cause that's indirectly related to the activist's primary agenda provides reasons to act in ways that are congruent with that agenda. In this paper, we consider the two indirect arguments that animal activists advanced in the early months of the COVID-19 pandemic: first, some used COVID-19 to criticize intensive animal agriculture - many of these had US-based audiences as their target; second, and more modestly, some activists used COVID-19 to condemn wet markets specifically. We contend that both arguments had the risk of backfiring: they risked promoting the very systems that are worst for animals. We then assess the moral significance of this risk, concluding that while it may have been permissible to advance these arguments, there were some serious moral considerations against doing so - ones that weren't addressed by flagging animal activists' concern for animals or any other stakeholder in the discussion. In both cases, we think there are plausible precautionary arguments against the strategies that these activists pursued. Additionally, in the case of arguments against wet markets specifically, we contend that the precautionary argument can be supplemented with a side constraint condition that, arguably, activists violated insofar as they were acting in ways that maintain a racist and xenophobic system.
\end{abstract}

Keywords COVID-19 $\cdot$ Animal advocacy $\cdot$ Wet markets $\cdot$ Factory farms $\cdot$ Activism

Alyse Spiehler

alyses@ad.unc.edu

Extended author information available on the last page of the article 


\section{Introduction}

There were excellent reasons to reform intensive animal agriculture prior to COVID-19. Intensive systems are subject to familiar objections concerning their impacts on the environment, workers, and public health. Additionally, and of particular note here, intensive systems have long imposed substantial burdens on nonhuman animals. In the short run, then, there are good arguments for increasing both the regulation and oversight of intensive systems; in the long run, there are good arguments for scaling them back and, in their place, encouraging plant-based food production.

Unfortunately, though, intensive animal agriculture has grown rapidly over the last century. All signs indicate that it will continue to grow in the future. At a global level, this is due to a combination of population growth and rising incomes (as income is correlated with demand for animal products) (Kearney 2010). As a result, many predict that rising demand will drive up global production by roughly 50\% over the next 30 years, and some estimates are higher (Alexandratos and Bruinsma 2012). This may be good news for those in the industry, but it's bad news for billions of animals. It's also bad news for those who want an animal-friendly food system.

Because the public isn't very concerned about the plight of animals - or is concerned, but has a high tolerance for cognitive dissonance - animal activists regularly engage in indirect activism. Indirect activism involves arguing that some cause that's indirectly related to the activist's primary agenda provides reasons to act in ways that are congruent with that agenda. Want to be healthier? Go vegan! Want to reduce your carbon footprint? Go vegan! Want to distance yourself from industries that exploit undocumented immigrants? Go vegan!

We aren't suggesting that these activists don't care about health, climate change, or the rights of immigrants. No doubt they do. Indirect activism needn't be - and, we presume, rarely is - disingenuous. Rather, it's indirect in the sense that the issue that's supposed to "hook" the audience isn't the one that's the primary motivation for the activism, even if it's an issue about which the activist is genuinely concerned; instead, it's an issue she hopes to use to motivate others to act in ways that fit with her primary objective. Most animal activists would be opposed to intensive animal agriculture even if, say, it were completely carbon neutral; they aren't opposed to intensive systems primarily for environmental reasons. Environmental reasons are, for them, secondary considerations, which is compatible with their being weighty considerations.

By "animal activists," we refer to people for whom helping animals is their primary objective. By definition, then, when animal activists used COVID-19 to argue for changes in the food system, they were engaging in indirect activism. (Granted, if we're mistaken in describing any particular individual as an "animal activist," in our specific, "animals first" sense of that phrase, then what we have to say won't apply to them. In the specific cases we mention, though, we think that these individuals are indeed animal activists, as evinced by their long careers in animal advocacy.) Specifically, after the COVID-19 outbreak became international news, many western animal activists began publishing articles arguing that their audiences should oppose both intensive animal agriculture in the West and/or wet markets in China based on their links to zoonotic diseases. We aren't suggesting that these activists don't care about zoonotic diseases. No doubt they do. We are only saying that these activists weren't primarily concerned with minimizing the risk of future pandemics. They were primarily concerned to help animals, but believed - plausibly enough - that the general public would be more responsive to arguments against intensive animal agriculture and / or wet markets based on pandemic threat mitigation, rather than to arguments based on animal welfare. 
In every case, these activists made it clear that they weren't only concerned about pandemic threat mitigation. Indeed, they often signaled that they took other considerations to be weightier. After a discussion of the risks to which intensive animal agriculture and wet markets expose human beings, David Benatar (2020), for instance, wrote that those risks provide "a self-interested reason - in addition to the even stronger moral reasons - for humans to treat animals better" (emphasis ours). They were trying to be both strategic and responsible: the former, by leveraging an issue of pressing public concern; the latter, by nudging people to consider the animal-centric reasons to reform or abolish animal-harming industries.

Activists have long worried about the risk of having their arguments backfire. There are, of course, familiar stories about people claiming that they will eat extra meat to make up for whatever vegans don't consume. But the more disturbing examples are the ones we wouldn't anticipate. One study, for instance, found that telling people about animal-free food technologies, including cultured meat and plant-based products that accurately imitate meat, actually reduced their opposition to raising and slaughtering animals for food. That is, people were less likely to criticize animal farming in the wake of learning about plant-based alternatives to animal products. ${ }^{1}$

Indirect arguments face a special version of this problem. They can, of course, backfire in the same way as direct arguments: they can increase resistance to the very cause they are trying to advance. In addition, however, they can backfire by partially succeeding. Consider arguments to the effect that you should go vegan for environmental reasons. One worry is that you may actually convince people to optimize their carbon footprints (for instance), but then they realize that they can better achieve that aim via non-vegan means - say, by eating insects that were fed agricultural waste. A related worry is that your audience may look for ways to improve their carbon footprint without completely sacrificing a kind of product they value. This may mean people switch from beef and pork to chicken and fish-products with smaller carbon footprints but dramatically higher harm footprints, as it takes so many more animals to produce the same amount of meat. Finally, people may look for ways of reducing the carbon footprint of a certain form of animal agriculture by, say, changing the kind of feed that's given to animals. It's certainly possible that such substitutions could be better in environmental terms while being worse for welfare. And obviously, in each case, the backfiring can occur even if you communicate, however clearly, that you think there are other, weightier, animal-centric reasons to go vegan.

This is a special kind of backfiring risk: your arguments can be partially successful while setting back the very cause you're trying to advance. This risk is unique to indirect forms of activism. Direct arguments on behalf of animals' welfare may be ineffective or counterproductive, but insofar as the arguments are at least partially successful —insofar as they lead people to give greater weight to animal welfare - that seems like a victory. Some indirect arguments, by contrast, including the ones at issue here, aren't like this. Instead, they run the risk of harming the activists' cause should they partially achieve their aims. A successful pandemic risk mitigation argument would result in an increase of pandemic mitigation efforts, but, as we hope to show, could have negative effects on animals' wellbeing.

In this paper, we consider the two indirect arguments that animal activists advanced in the early months of the COVID-19 pandemic: first, some used COVID-19 to criticize intensive animal agriculture - many of these had US-based audiences as their target; second, and more

\footnotetext{
${ }^{1}$ https://www.sentienceinstitute.org/downloads/The\%20Effects $\% 20$ of $\% 20$ Animal-Free $\% 20$ Food $\%$ 20Technology\%20Awareness\%20on\%20Animal\%20Farming\%20Opposition.pdf
} 
modestly, some activists used COVID-19 to condemn wet markets specifically. We contend that both arguments had the risk of backfiring: they risked promoting the very systems that are worst for animals. We then assess the moral significance of this risk, concluding that while it may have been permissible to advance these arguments, there were some serious moral considerations against doing so - ones that weren't addressed by flagging animal activists' concern for animals or any other stakeholder in the discussion. In both cases, we think there are plausible precautionary arguments against the strategies that these activists pursued. Additionally, in the case of arguments against wet markets specifically, we contend that the precautionary argument can be supplemented with a side constraint condition that, arguably, activists violated insofar as they were acting in ways that maintain a racist and xenophobic system.

We have two aims in all this. First, and most obviously, we hope to advance the conversation about the ethics of using pandemic risk to advance animals' interests. Second, we hope to raise a more general question about how to assess the ethics of indirect activism - $\mathrm{a}$ question that hasn't received the attention it deserves.

The plan for the paper is as follows. In the next section, we explain why COVID-19-based criticisms of intensive animal agriculture created backfiring risks. Then, in Section 3, we turn to those risks for COVID-19-based criticisms of wet markets. We spend Section 4 on the precautionary arguments against taking these risks. We devote Section 5 to substantiating a charge we level in Section 4 to the effect that activists criticizing what markets were violating a side constraint. We conclude with some tentative thoughts about how the risk of backfiring, and worries about structural racism and xenophobia, could have been navigated better.

\section{Using COVID-19 against Intensive Animal Agriculture}

With these preliminaries behind us, let's turn to the way that animal activists used COVID-19 to criticize intensive animal agriculture. Consider some of the op-eds that circulated in early 2020: "Coronavirus Should Make You Reconsider Eating Meat," "A Palate for Pestilence: Ominous Links Between COVID-19 and Industrial Animal Farming," and "To Reduce the Risk of Pandemics, We Must Ban Factory Farms Now." In each case, the author(s) were trying to get Western consumers to boycott intensive animal agriculture in their own countries. In the first of those essays, for instance, the author wrote that "[e]very time we buy animal products, we directly sponsor a system that will continue to produce pandemics... Our food choices need not personally contribute to the risk of a public health crisis. Perhaps it's time we take pandemics off our plates" (Murphy 2020). This general anti-industrial farming message was also at the heart of other activists' articles, whose takeaways are summed up in the warnings: "we must ban factory farming, effective immediately" (Warden 2020), and "intensive animal farming unquestionably poses a grave, pandemic-level threat to human and animal health" (Stubler and Sebo 2020).

\footnotetext{
${ }^{2}$ For these titles, see: https://sentientmedia.org/coronavirus-should-make-you-reconsider-eating-meat/; https:// sentientmedia.org/ominous-links-between-covid-19-and-industrial-animal-farming/; https://sentientmedia.org/toreduce-the-risk-of-pandemics-we-must-ban-factory-farms-now/. For additional articles with the same message, see: https://thehill.com/opinion/energy-environment/491066-reducing-pandemic-risk-begins-with-endingfactory-farming; https://www.latimes.com/opinion/story/2020-04-02/coronavirus-pandemics-animals-habitatecology; https://www.nationalreview.com/magazine/2020/04/06/senator-booker-is-right-about-factory-farming/; https://www.wired.com/story/opinion-modernizing-meat-production-will-help-us-avoid-pandemics/; and https:// www.theguardian.com/commentisfree/2020/apr/16/coronavirus-covid-19-pandemic-food-animals/.
} 
There is some truth to this, of course. There are links between animal farming and disease outbreaks: the swine flu, the avian flu, and SARS emerged from farming operations, just to name a few familiar viruses (Jones et al. 2013). What's more, because so many antibiotics are fed to healthy farm animals, people the world over are at risk of antibiotic resistant superbugs that could create new pandemics (AMR Review 2015). It's also plain that the rate of novel strains of zoonotic influenza emerging in humans has increased in recent years, making the risk of pandemics more pressing than before (Bui et al. 2017). So, it's no mistake to highlight the link between animal farming and zoonotic disease. However, insofar as activists make zoonotic disease the central issue, there are good reasons to worry about their arguments backfiring. This is because (1) the pandemic-based case against intensive animal farming is weaker than these activists suggested and (2) given the degree to which animal agriculture is entrenched around the globe, the most likely response to concerns about pandemic risk are animal welfare-reducing policies.

\section{Intensive Animal Agriculture and Pandemic Risk}

Viruses like COVID-19 derive from either wildlife itself or wildlife/livestock interactions. As Jones et al. (2013) argue, farming systems "that allow contact between wild and domestic birds and pigs and have large high-density populations that facilitate transmission, adaption, and amplification" generate the greatest threat. While it's possible for viruses to take root and spread whenever animals are densely packed together, the evidence overwhelmingly supports the idea that the greatest risk for emerging infectious diseases are in places with "a rapid intensification of agricultural systems, especially of livestock keeping, and increasing interactions between animals, humans, and ecosystems," often caused by rapidly changing habits and practices within societies (emphasis ours) (Lindahl and Grace 2015). These risk factors are exactly what industrial indoor farming operations are designed to avoid; as a result, the risk of viral outbreak from those systems is much lower. We aren't saying that diseases like H1N1 can't be traced back to factory farms. Instead, we're saying that these risks are manageable, and in the United States, we have reason to think that these risks are fairly well managed. It's no coincidence that none of the viral outbreaks that have emerged from intensive farms emerged from U.S. operations. After all, these farms are designed to isolate animals from natural environments, the number of humans interacting with these confined animals is relatively low, and farm workers take measures to disinfect themselves before interacting with the animals. Consider that losing an entire herd or flock to viral outbreak isn't only dangerous to human health, it's expensive - and U.S. intensive farming operations are optimized for cost effectiveness. What's more, this style of farming is becoming increasingly common elsewhere, and some Chinese companies are pushing this model further than any U.S. firms have attempted. Yangxiang, a Chinese firm, recently built a 12-story pig farm that is designed to bring 840,000 pigs to slaughter weight each year - at least an order of magnitude more than many intensive U.S. farms - with tighter biosecurity measures than are standard here. ${ }^{3}$ So, activists' focus on a viral pandemic outbreak is not a very compelling objection to US-styleor, now, Chinese-style - intensive farming.

Granted, the risk of antibiotic resistant bacteria isn't being managed in the way that viral outbreak risk is being managed. Is it the case, then, that Western audiences should be as

\footnotetext{
${ }^{3}$ https://www.theguardian.com/environment/2020/sep/18/a-12-storey-pig-farm-has-china-found-a-way-to-stopfuture-pandemics-
} 
concerned over this threat as they were about viral outbreak, as some animal activists suggested? We suspect they should be, but it doesn't follow that factory farming should end.

Intensive farming operations tend to cultivate antibiotic resistant bacteria as a result of subtherapeutic antibiotic use, which is a preventative measure against infections that's designed to lower morbidity and maintain high growth rates. Subtherapeutic antibiotic use selects for bacteria that lack the vulnerabilities the antibiotic exploits, eventually creating a reservoir of those bacteria in animal populations (Pew 2008). Such bacteria pose a serious risk to human health as humans rely on many of the same antibiotics that producers use on animals. While this process indeed results in human deaths, COVID-19 has caused far more, and in any case, animal agriculture is directly responsible for a relatively small percentage of them. A 2019 report by the CDC shows that nearly three million antibiotic-resistant infections occur in the U.S. each year, and more than 35,000 people die as a result (CDC 2019a). While this is a significant number of deaths, all six urgent bacterial and fungal threats - as classified by the $\mathrm{CDC}$ - are unrelated to factory farms. Of those six most urgent threats, five emerge in healthcare systems (CDC 2019a). Campylobacter, the most common animal borne bacteria and a "serious threat," is preventable if consumers don't consume raw chicken, and it almost never kills patients who become infected with it (CDC 2019b). Salmonella, the second most serious animal borne bacteria, kills 420 people in the U.S. each year (CDC 2020). By contrast, around 550,000 people have died of COVID-19 in the U.S. as we write this. If there weren't a single additional American death due to COVID-19, it would take well over a thousand years to have an equivalent death toll from food-borne salmonella.

It's true, of course, that the antibiotic doomsday scenario is far worse than the current state of affairs. Aslam et al. (2018) point out that if we weren't to have any effective antimicrobials, roughly 444 million additional people would die by 2050 . However, we aren't in the doomsday scenario, there are enormous resources being devoted toward the development of new ways to deal with antibiotic resistant pathogens (some not involving antibiotics at all; see, e.g., Wang et al. 2020), and there are several reasons to think that the animal-agriculturespecific component of the problem is manageable (especially compared to the problem of managing risks in wildlife markets).

Some of the strategies for managing the animal-specific component of the risk are regulatory. In 2015, the FDA issued the Veterinary Feed Directive final rule, which bans the use of certain antibiotics for growth promotion based on their being medically significant for humans. This rule is imperfect, as it allows veterinarians to prescribe essentially the same drugs, and only prevents producers from purchasing them directly from wholesalers without a medical justification. Still, the rule is indicative of the kind of measures that would significantly reduce the threat that animal agriculture poses to human health (at least along this one dimension). Some U.S. legislators have already proposed more aggressive strategies. The Preservation of Antibiotics for Medical Treatment Act, introduced by Louise Slaughter (D-NY), would

[amend] the Federal Food, Drug, and Cosmetic Act to require an applicant for approval of a new animal drug that is a medically important antimicrobial to demonstrate that there is a reasonable certainty of no harm to human health from antimicrobial resistance attributable to the nontherapeutic use of the drug (Congress 2017).

This bill is a long way from becoming law, not least because it's opposed by various industry groups. Still, regulation represents one way forward when it comes to managing pandemic threat from intensive animal agriculture. In the case of the wildlife trade, it isn't feasible to address the risks via regulation. Simply put, these risks can't be mitigated if animals are 
extracted from the wild itself, if domesticated animals are being raised in farms where they regularly interact with wildlife, or if wild and domesticated animals are slaughtered and sold in dense urban settings. Ultimately, these practices will have to end to reduce zoonotic outbreak threat—but as we'll see in Section 3, this isn't the fault of wet markets generally.

If U.S. regulation of nontherapeutic antibiotic use fails, though, there are other ways in which the industry can deal with the antibiotic resistant bacteria problem, especially if consumers demand it. In 2011, researchers from Cambridge created chickens whose genomes had been modified so that they were less likely to propagate avian influenza. This particular modification didn't stop the infected birds from dying, but it did prevent them from passing the infection on both to transgenic and conventional chickens. The researchers claim that because "the transgene encodes an innocuous decoy RNA, expressed at steady-state levels that are barely detectable by conventional methods," it is "unlikely to present a risk to consumers, birds, or the wider environment," and there "are no apparent ill-effects on uninfected transgenic birds, which are phenotypically normal" (Lyall et al. 2011). Obviously, there are questions about the effectiveness of these genetic modifications when it comes to novel infections, questions about the prospects for similar developments other species, and the challenge of getting regulators and consumers to accept product from genetically modify animals. However, while the risk of novel threats always needs to be managed, changes in production methods can help there (as discussed above). While there hasn't been any published research on, say, swine flu resistant pigs, there has been other research on modifying pigs to improve their suitability for CAFOs (Zhang et al. 2018). And, of course, the example of AquAdvantage salmon - genetically modified for faster growth, approved by the FDA for sale to U.S. consumers in 2015 - shows that, at least in principle, the regulatory hurdles can be overcome. $^{4}$

Granted, pandemic risk would be lower without intensive systems. But insofar as we leave a certain anthropocentric perspective in place, abolishing intensive systems would be an overreaction. After all, from that anthropocentric perspective, intensive systems are an enormous net good: they produce vast amounts of highly desirable animal-based foods and byproducts at prices that have never been lower as a percentage of average annual income.

\section{The Backfiring Problem}

With that in mind, what is the most likely response to concerns about pandemic risk? To get at this issue, let's consider the response that activists should have expected. If consumer trends were any indication, it wasn't individual change. After all, immediately following the lockdowns, there was a dramatic run on animal products in response to shelter-in-place orders. Meat prices were on the rise, production was up, and consumers were stockpiling as much as they could. ${ }^{5}$ Despite almost constant discussion of COVID-19 in the press, consumers didn't seem to be quick to make connections between contemporary intensive systems and an international viral outbreak (Anderson 2020). Activists had no reason to suspect that consumers would turn on a dime to put pressure on the intensive animal agriculture industry. And even if some did, perhaps as a result of advocacy efforts of the type we mentioned above, there

\footnotetext{
${ }^{4}$ Admittedly, AquAdvantage salmon isn't currently for sale in the U.S. because the FDA is dragging its feet on labeling standards for genetically modified animal products. It is, however, for sale in Canada.

${ }^{5}$ For information on stockpiling, see: https://www.iriworldwide.com/IRI/media/Library/COVID-19-ThoughtLeadership-4-3-2020.pdf. For information on price and production increases, see: https://lmic.info/
} 
was no reason for activists to suspect that the industry would fold to demands for abolition. (The Meat Institute, an industry lobbying group, actually responded to one of the more prominent activist op-eds, arguing that "Although the precise origin of Covid-19 is still being determined, ongoing research continues to confirm that domestic livestock production is safe and has not played a role in the spread of Covid-19" (NAMI 2020). Given this, the likeliest outcome was, and still is, the industry pursuing the most economical ways of managing the threat of future pandemics: namely, isolating livestock from wildlife.

Conveniently for the industry, the intensive systems that best manage this are also the most productive, increasing the incentive. (They are expensive to build, which explains why they aren't in use universally already.) Plainly, though, this is bound to have negative results for farmed animals' welfare, as it means (further) restricting outdoor access, fresh air circulation, natural light, and so on (for the animals that have it), or it simply means that a greater number of animals survive to lead the disappointing lives that are available to them. Pandemic risk was and is real, but insofar as the industry ever listens, the reasonable thing to expect was that producers would work to minimize the threat - not reduce production or improve animal wellbeing.

Despite these considerations, someone might insist that it was wise to make links between COVID-19 and intensive animal agriculture. They might argue as follows. Animal agriculture is growing fastest in the developing world, and while some countries now have state-of-the-art operations - usually as a result of foreign investment - many of the new intensive operations still permit much more livestock/wildlife interaction than we find in, say, North Carolina hog farms, which are fairly tightly controlled. So even if U.S. intensive animal agriculture is relatively unlikely to generate the next pandemic, intensive animal agriculture generally creates higher risk levels. It's a good thing, therefore, to promote the idea that there's a link between COVID-19 and intensive animal agriculture, because while the link isn't particularly strong in the US, it's stronger elsewhere.

There are two basic problems with this objection. The first is that there wasn't, and still isn't, any good reason to believe that U.S. consumers' decision to see animal agriculture as a threat would slow the process of agricultural intensification globally. If the goal is to reduce pandemic risk, it doesn't really matter whether U.S. consumers are opposed to intensive farming. Indeed, it would hardly matter if U.S. consumers stop eating animal products entirely. We have every reason to think that animal agriculture is going to grow dramatically in the developing world for reasons already mentioned: namely, population growth and rising incomes. These trends aren't going to be undermined by shifts in public opinion in the wealthiest countries. This argument is, therefore, disingenuous, and risky for that reason. It makes sense if the real objective is to reduce demand for animal products in the U.S., in hopes of driving down production, but not if our main objective is to avoid future COVID-19-style crises. However, the intended audience is composed of people who are just concerned about pandemic risk, not the welfare of farmed animals. Thoughtful readers, then, may well recognize that the argument doesn't show what it's supposed to, which undermines the credibility of the activists who advanced the argument in the first place.

The second problem with the idea that activists should have been promoting a link between COVID-19 and intensive animal agriculture is related to a risk that we mentioned earlier. What was the most likely response to worries about pandemics? Again, not ending intensive animal agriculture. While intensive agriculture elsewhere may be riskier than it is in the U.S. at the moment, the U.S. isn't the only country that can implement successful viral outbreak mitigation measures. So, we should expect an increase in forms of agriculture that satisfy consumer 
demand while minimizing livestock/wildlife interactions - namely, forms of agriculture that involve more extreme forms of confinement for the sake of public health, but with obvious costs in terms of animal welfare. Should the concern over food system-related pandemic outbreak become an international issue, we don't have reason to expect that the people of Tanzania, Nicaragua, and other countries involved in the process of rapid farming intensification will stop wanting the cheap chicken that citizens of wealthier countries have enjoyed for years. They will just find ways of having it that are less dangerous. And those ways won't be good for animals.

Indeed, they may be even worse that we've suggested so far. Essentially, there is no pandemic risk due to fishing, aquaculture, or insect farming. But animal activists are increasingly concerned about these activities, given the trillions of animals involved. If the industry were to turn away from intensive animal agriculture to these alternatives, it might be far worse from the perspective of the very activists who called for change.

The upshot is this. Even when activists were making these arguments, there were grounds for concern about arguments against intensive animal agriculture based on COVID-19. What's more, activists have long known about worries regarding indirect arguments on behalf of animals, trends in individual purchasing, and the industry's ability to tighten biosecurity measures or breed disease-resistant animals rather than make the changes activists desire. So, the risk of backfiring should have been on their horizon. Animal activists, then, had reason to attend to the risks to farmed animals that accompany a focus on pandemic threat.

Granted, the possibility of backfiring doesn't show that this instance of indirect activism was wrong. There are always risks, and risks have to be balanced against potential rewards. We will say more about this later. For now, we simply want to register that the risk was real.

\section{Using COVID-19 against Wet Markets: Backfiring}

Of course, as we mentioned at the outset, some animal activists didn't use COVID-19 to challenge intensive animal agriculture generally. Instead, they called for the end of wet markets specifically (e.g., Stubler and Sebo 2020; Singer and Cavalieri 2020, and Benatar 2020). ${ }^{6}$ What, exactly, were they criticizing?

Wet markets take many forms in China (and in Southeast Asia generally), ranging from pop-up farmers markets to permanent, brick-and-mortar establishments. They are unified by their being composed of vendors with independent stalls, as opposed to a conventional grocery store with departments that are part of a single business. Wet markets pose a risk because viruses like COVID-19 derive from either wildlife itself or wildlife/livestock interactions. If wet markets sell wildlife directly, sell animals who have interacted with wildlife, or create conditions where wildlife and livestock can interact (as occurs in a small number of wet markets where wildlife and livestock are housed and slaughtered on site), then they put humans at risk of contracting zoonotic diseases.

However, the concern about backfiring is just as pressing here as it was when COVID-19 was marshalled against intensive animal agriculture. What would happen if those in power listened to activists' objections to wet markets? Presumably, most of the people who shop at them won't abstain from consuming animal products; instead, most of those consumers would

\footnotetext{
${ }^{6}$ Animal Equality also formally campaigned for a ban on wet markets: https://www.youtube.com/watch?time_ continue $=4 \& v=W x t Z j 1 \_z W 20 \&$ feature $=e m b \_$title.
} 
start shopping for them at conventional grocery stores. And those stores, of course, would largely supply those products from intensive agricultural systems. So, rather than benefiting animals on net, the end of wet markets - and the fact that small-scale farmers would face greater difficulty in selling their animal products - would probably mean an increase in (more or less well-managed) intensive farming systems. Indeed, there is already pressure from mainstream supermarkets in China to ban wet markets, as that would increase their market share. Likewise, we should expect Western investors to see the closing of local farmers and their operations as a prime opportunity to continue a trend that we already see unfolding: namely, the investment in intensive farming operations that provide lots of low-cost animal products to foreign markets. Major Western companies like Tyson are already investing in operations in countries across Asia and Africa, and we would only expect that practice to spike if the already disadvantaged competition - local farmers - were prohibited from selling their products. ${ }^{7}$ In all, then, even if local farmers and the markets in which they sell were shut down in favor of supermarket alternatives, there was (and is) no reason to expect that China will suddenly go vegan in its efforts to stock supermarket shelves. Instead, in China as in the U.S., activists should predict that a new wave of intensive farming would replace wet markets and small-scale farmers - which is no good for animal welfare.

\section{A Precautionary Principle}

In the preceding sections, we've argued that both of the arguments that animal activists made during the early months of the pandemic — both against intensive animal agriculture and wet markets - ran the risk of backfiring. However, the mere possibility of backfiring doesn't show much of anything. To move from that possibility to a moral conclusion, we need some additional normative considerations. In this section, we consider the potential relevance of a precautionary principle.

The most straightforward way to think about the ethics of risk is via an expected utility calculation. To run one, we would assign probabilities and utilities to the various backfiring outcomes, as well as probabilities and utilities to the outcomes that activists hoped to achieve, all based on the evidence that activists had available to them at the time. Then, we would assess whether it was worth running these risks by assessing the expected utility of publishing arguments against intensive animal agriculture and wet markets. Arguably, though, these probabilities were, and perhaps still are, inscrutable. There was simply too much uncertainty about all the factors known to be relevant, not to mention an untold number of unknown unknowns. At any rate, we will assume inscrutability here.

When probabilities are inscrutable, the standard move is to rely on some sort of precautionary principle. Granted, precautionary principles are vulnerable to a series of standard objections. For instance, some precautionary principles can generate contradictory results. Many precautionary principles can be accused of failing to give sufficient weight to the benefits that might be realized. And it's often the case that precautionary principles smuggle in a range of normative considerations that go unanalyzed. (For an excellent survey of these challenges, see Newman et al. 2017.) Nevertheless, if we are generally unsure how to complete

\footnotetext{
${ }^{7}$ For just two examples of this trend, see: https://www.theguardian.com/environment/2018/dec/27/its-gods-planthe-man-who-dreams-of-bringing-intensive-chicken-farming-to-africa and https://www.tysonfoods.com/news/ news-releases/2019/2/tyson-foods-acquire-thai-and-european-operations-brf-sa
} 
the expected utility calculation, it's unclear where else to turn. So, we will have to do our best with a precautionary principle.

But which one? Here, we will assume that activists have a fiduciary responsibility to the beings for whom they advocate. Fiduciaries typically are bound by duties of loyalty and care: they ought to do what's in the best interest of their beneficiaries, and they ought to exercise due diligence in that effort. One way of checking to see whether activists are fulfilling those duties is to consider what their beneficiaries would want them to do. Unfortunately, animals can't speak for themselves to tell us their preferences regarding difficult trade-offs of this kind. But we might think that, just as many humans prefer to eliminate any chance of falling into the worst possible outcome, even if it means sacrificing the best possible outcome, we ought to do the same for animals. In other words, when the probabilities of outcomes are inscrutable, we ought to employ some sort of maximin principle.

Given this, how might we specify the relevant precautionary principle? A first pass might be: activists should avoid taking a non-trivial risk of leaving their beneficiaries seriously worse off due to their efforts. If that's the principle that we employ, then it seems that some animal activists violated it during the early months of the pandemic. The arguments we've offered indicate that the risk wasn't trivial, and had those risks been realized, many animals would have been seriously worse off. ${ }^{8}$

Granted, some activists might reject the assumption that the probabilities are inscrutable and try to defend their actions based on expected utility calculation. Others might argue that the risk of backfiring was indeed trivial or that animals wouldn't be significantly worse off. We have nothing further to say about these criticisms; we would just be reiterating what we've said above.

A different criticism is more pressing. Consider the activists who concede what we've argued about the probabilities being inscrutable, the risk of backfiring not being trivial, and the claim that animals would be significantly worse off in such circumstances. However, these activists argue that it would have been equally risky not to make these indirect arguments. After all, the activists might say, quarantine orders and overflowing ICUs made pandemic threat highly salient to huge swaths of the population. If concerns about that threat could have been marshaled for animals, then significant change might have been possible. Could we really justify not gambling for animals' sake? In so doing, wouldn't activists have been taking a nontrivial risk of leaving animals much worse off than they could be, which seems objectionable too?

If activism of any kind is ever justified - whether direct or indirect - this reply to precautionary reasoning must work in at least some cases. And we grant that activism is often justified. So, our claim here is just that there is an asymmetry between direct and indirect activism that makes direct activism less risky than indirect activism, which is a reason to prefer direct strategies. As we discussed earlier, direct arguments can be ineffective or counterproductive, but that's all: there isn't much reason to worry that the arguments will be received sympathetically while setting back the activists' agenda. In the case of these indirect arguments, there are the same risks about the arguments being ineffective or counterproductive as a result of the arguments not being convincing. In addition, however, there is a risk of the argument being convincing, at least partially, and backfiring for that reason. So, given that

\footnotetext{
${ }^{8}$ Or, insofar as they wouldn't have been seriously worse off, it would be for reasons relating to the non-identity problem. We will simply set that issue aside here, assuming that whatever solution we choose for the non-identity problem will also apply in the present case.
} 
there is this additional way to fail, it would seem that precautionary reasoning favors not running these arguments unless there are sufficiently weighty reasons to think that this additional risk vector is outweighed by the good that the activism might accomplish. The defender of indirect activism will argue that this condition is met by the opportunity to leverage a matter of independent public concern. But if the probabilities of both success and the relevant forms of failure really are inscrutable (all low, but not precisifiable beyond that), then this condition is not met. In such circumstances, the reason to be optimistic about success is just the fact that the matter of independent public concern - the environment, or pandemic risk, or what have you - really is a matter of public concern. That, however, is the very reason we should worry about backfiring, since its being a matter of public concern means that people may favor ways of addressing the concern that, ultimately, are contrary to the aims of the indirect activist.

We have, then, a prima facie plausible case against the strategies that some activists pursued in the early months of the COVID-19 pandemic. However, we think we can go further in the case of the arguments against wet markets specifically. Here is a yet-more plausible precautionary principle: activists should avoid taking a non-trivial risk of leaving their beneficiaries seriously worse off due to their efforts, when, in running that risk, they would be acting in ways that are morally objectionable for independent reasons. In the section that follows, we hope to show that running anti-wet market arguments in particular violated this side constraint, which makes the case against those running arguments stronger still.

\section{Using COVID-19 against Wet Markets: Racism and Xenophobia}

In this section, we argue the arguments animal activists ran against wet markets were, however unintentionally, racist and xenophobic. Hence, if running those risks was already objectionable based on precautionary reasoning, it's more objectionable still insofar as activists acted in ways that sustain racist and xenophobic systems. To be clear: we aren't making any claims about the psychologies of the activists. We assume, in fact, nothing but goodwill. Instead, we are making a claim that's common in discussions of systemic racism and xenophobia - namely, that failure to resist the ideas, customs, laws, and institutions that sustain racist and xenophobic systems is generally a way of maintaining racist and xenophobic systems. According to structural account of racism, actions are racist when they are tokens of a type of action that, in a particular social context, maintain these forms of injustice. Failure to resist is, in that sense and for that reason, racist and xenophobic. And, we presume, it's morally objectionable to act in that way.

The upshot is that even if actions are performed with the best of intentions, without the least racial ill will, they can nevertheless be racist because of the context in which they occur. With that in mind, we need to say more about the context in which activists were leveling critiques of wet markets.

\section{The Importance of Wet Markets}

Wet markets are an important part the Chinese food system. Even though supermarkets are an available alternative to many urban Chinese people, "wet markets continue to be the most significant fresh food source in many metropolises" (Zhong et al. 2020). These markets offer fresh food, including animal products, but also fruits and vegetables. And in a study surveying the importance of freshness in consumers' choices within their food systems, researchers found 
that "freshness has become the foremost priority among food shopping concerns, and the pursuit of such freshness is closely associated with the use of wet markets" (Zhong et al. 2020).

What's more, wet markets "carry a variety of fresh foods at low cost, providing a price advantage over supermarkets," meaning that they will be of particular importance to lowincome citizens (Zhong et al. 2018). A study conducted in Nanjing City reveals that "wet markets have conventionally been the dominant outlet for healthy food," and vastly outnumber their supermarket counterparts, making up $85 \%$ of consumers' store choice (Zhong et al. 2018). Wet markets also help to ensure that $90 \%$ of households in Nanjing can engage in the practice of purchasing their fresh foods within walking distance, facilitating the cultural practice of daily food shopping: $70 \%$ of households shop at wet markets at least five days a week, compared to $17 \%$ of households who shop this frequently at supermarkets (Zhong et al. 2018). Indeed, one expert recently cautioned that wet markets' abolition would be "destructive for urban food security in China."9

Additionally, it's important to recognize that most wet markets do not have live animals who are slaughtered on site. Indeed, wildlife consumption is associated with wealth, and one recent survey found that $97 \%$ of Chinese respondents were "strongly opposed" to it (Xinhua Net 2020). ${ }^{10}$ While we might doubt that these numbers are representative of the general population, they certainly suggest that wildlife isn't a mainstay in the average Chinese person's diet. Moreover, due to the economic realities that keep wet markets central to the Chinese food system, it would be surprising to find them full of expensive and unpopular foods, such as bats or pangolins - the animals presumed to be the original vectors for COVID-19's transmission to humans (Lam et al. 2020).

In short, then, to call for the end of wet markets is to call for the end of a system that is of particular benefit to low-income citizens. It would hurt consumers insofar as it would deny them access to fresh, inexpensive food via a culturally important foodway. It would also hurt small-scale producers. Throughout many parts of Asia and Africa, there are families that depend on low-intensity subsistence livestock farming (Tomley and Shirley 2009). Granted, in contexts like these, there are limited resources for "disease control, housing or feed supplementation" (Tomley and Shirley 2009). Herds are often kept in close contact with each other, with nondomestic animals, and with humans. Should this close contact persist in wet markets, there are clear paths for zoonotic disease transmission. But these same farming systems are closely linked to the wellbeing of populations who engage in subsistence farming, as they are "critical to sustaining local food supplies, alleviating poverty through income generation and for nutritional status," and so are more vulnerable than communities elsewhere, such as the United States (Tomley and Shirley 2009). Blaming these systems puts pressure on already vulnerable communities where farming is a key source of revenue as well as food supply, and where farmers selling these goods at wet markets is key to their livelihoods.

\section{The Political and Social Context}

Additionally, it's important to recognize that the kind of anti-wet-market arguments that activists were making had been weaponized in the past, and were being weaponized against

\footnotetext{
${ }^{9}$ https://www.bloomberg.com/news/articles/2020-04-08/wuhan-is-returning-to-life-so-are-its-disputed-wetmarkets

${ }^{10}$ Additionally, the WWF commissioned a study across five Asian markets, and found that $72 \%$ of respondents said they "never consume wildlife products," even before the pandemic (2020).
} 
Chinese people at the beginning of the COVID-19 pandemic. For instance, members of the political elite used their power to promote the idea that foreign food systems are to blame for the COVID-19 pandemic. Donald Trump insisted upon calling COVID-19 the "Chinese virus" in the early phases of the virus' spread in the United States, and often referred to it as "the plague from China" for the remainder of his term. In response to the backlash against his rhetoric early on, Trump insisted that this term was "not racist at all" because the virus "comes from China" (Stevens 2020). ${ }^{11}$ However, this verbal link invited people to make harsh and sweeping claims about Chinese culture as they expressed their anger over the virus. Senator John Cornyn of Texas, for example, publicly stated that China is to blame for the virus because it has a "culture where people eat bats and snakes and dogs and things like that."12 This link between COVID-19 and China became a simplistic way of having a culture stand in for a grave harm, which encouraged Americans to blame China for the crisis generally.

Consider, for instance, the way that Don Luskin commented on the COVID-19 outbreak while on FOX News, a platform that allied itself with Trump and that he long used as a way of promoting his ideas:

Bat soup may be delicious to certain people but unfortunately bats are the world's greatest reservoir for viruses. What are we gonna do about China? What are we gonna do about a totalitarian dictatorship where it's OK to sell live virus-infected bats in open air marketplaces and then have business travel and tourists travel between that country and the civilized world ${ }^{13}$

Luskin's contrast between China and "the civilized world" was anything but innocuous. The equation of cultural practices with anti-American totalitarianism and the spread of a global pandemic leaves uncritical viewers with the impression that Chinese culture and practices were to blame for the destabilization of "civilized" nations. This language also clearly divided the world into a "civilized us" and "uncivilized them," encouraging Luskin's audience to see themselves as combatants against the destabilizing forces of Chinese culture and, importantly, against those people without whom that culture wouldn't exist.

Political elites weren't alone in this rhetoric. One tweet with over 12,000 likes claimed that no one should be surprised that eating "bats and bamboo rats and shit" as "Chinese [delicacies]" would lead to diseases like COVID-19. ${ }^{14}$ Of course, it's not consumption of the species itself that poses a particular risk for zoonotic disease outbreak, but thousands of Twitter users seemed happy to make the same mistake that Luskin made on national media. Another widelycirculated post featured a map comparing the spread of COVID-19 to a map pinpointing all sanctuary cities - the disease hot spots correspond with the sanctuary city pins - and was captioned "Interesting, isn't it?"15 The implicit idea here is that the presence of undocumented foreigners was related to the spread of COVID-19. And although many Facebook users were quick to point out that this correlation is better attributed to population density than to undocumented foreigners' presence in the US, that didn't stop thousands of users from sharing the post. What's more, figures like Paul McCartney entered the discussion, calling bat eating

\footnotetext{
${ }^{11}$ Backlash didn't stop GOP House leader Kevin McCarthy from following Trump's lead and calling COVID-19 the "Chinese Coronavirus:” https://twitter.com/GOPLeader/status/1237165063565447168

$12 \mathrm{https}: / /$ twitter.com/thehill/status/1240364608390606850?s=20

${ }^{13}$ Emphasis ours https://www.youtube.com/watch?v=c09m5f7Gnic.

${ }^{14} \mathrm{https}: / /$ twitter.com/leafvillage33/status/1220204634851037184

15 https:/www.facebook.com/photo/ ?fbid=10222109627992510\&set=a. 1020240354515275
} 
"medieval" and comparing the long-standing tradition of wet markets to the long-lasting institution of slavery (Alexander 2020).

Of course, xenophobia in the news and online needn't translate into in-person acts of racism. But while it needn't, such acts were perpetuated in local communities. Multiple Asian Americans' stories made the news, exposing the ways in which these people were made victims of racist attacks after the COVID-19 outbreak. One woman described a stranger shouting, "Get out of here. Go back to China. I don't want none of your swine flu here," in one week, and then being threatened by a man wanting to shoot her the next (Escobar 2020). A man on a bus in Boston muttered about "diseased Chinese people" when a woman nearby sneezed into her sleeve" (Escobar 2020). Children have also been targeted, as Devin Cabanilla's children were while at Costco. A sample vendor told Cabanilla's "Korean wife and mixed-race son to 'get away' from the samples, questioning whether they had come from China" (Escobar 2020). A thirteen-year-old described tensions at school when her middleschool classmates started calling her "corona" and asked if she and her Asian American peers ate dogs (Escobar 2020). And such incidents weren't confined to the United States. In Australia, some parents refused to let Asian doctors treat their kids (Escobar 2020). In Canada, 10,000 people signed a petition asking a local school district to track down and isolate Chinese-Canadian kids after the Lunar New Year (Escobar 2020). In London, a man was attacked by a mob of four people who punched and kicked him to the point that he was told he may need facial reconstructive surgery (Haynes 2020). In the U.S. and elsewhere, at school, at work, and in public, the COVID-19 outbreak was followed by acts of racism that harmed members of already marginalized communities.

None of this should be particularly surprising, as this is hardly the first time that some Americans have responded in these sorts of ways. In 1853, during the yellow fever epidemic, European immigrants were stigmatized since they were said to be more vulnerable to disease, to the point that the epidemic was nicknamed "The Strangers' Disease" (Carrigan 1970). ${ }^{16}$ In the plague of 1899, health officials in Hawaii quarantined "Chinatown" first - a home to Chinese, Japanese, and Native Hawaiian residents - responding to the belief that Asians "were more susceptible to the bubonic plague than Europeans" (Mohr 2005). A common public perception was that white people were protected from infection, with at least one local newspaper giving credence to this belief when it reported that the plague "was not dangerous to whites "who were honest and cleanly" (Mohr 2005). ${ }^{17}$ In an attempt to sanitize communal spaces with controlled fires, Chinatown was accidentally burned down in January of the following year. In 1924, the bubonic plague prompted Los Angeles officials to quarantine and guard Mexican-American neighborhoods, including those where there was not disease outbreak (Deverell 2004). Officials expressed their hope that "all of that area where Mexicans live [be put] in sanitary condition" and urged that "a great deal of that area ... ought to be condemned and destroyed" (Deverell 2004). This destruction ensued, in the name of sanitation, and the government refused to pay any compensation since the destroyed propertieshouses, business, infrastructure, and the like-were construed as public health nuisances (Deverell 2004).

\footnotetext{
${ }^{16}$ For more detail on the link between the yellow fever outbreak and racism, see: https://www.npr.org/sections/ codeswitch/2018/10/31/415535913/how-yellow-fever-turned-new-orleans-into-the-city-of-the-dead.

${ }^{17}$ For more on the history of racism and disease outbreak, see: https://www.citylab.com/equity/2020/03/ coronavirus-racism-disease-chinatown-bubonic-plague-honolulu/608149/ and https:/www.theatlantic.com/ international/archive/2020/03/coronavirus-covid19-xenophobia-racism/607816/
} 
During more recent outbreaks, too, like those of SARS and Ebola, xenophobia was part of the public chaos. The SARS outbreak saw similar repercussions to those we enumerated earlier. A cartoon illustrated during that time features an open Chinese food takeout container with "SARS" written on it, and bearing the caption, "Bad Chinese Take-Out" (Shoichet 2020). Claire Jean Kim discusses this phenomenon in her work, identifying the way in which "tropes of Chinese cruelty, transgressiveness, backwardness, and recklessness," took the media by storm during the SARS crisis (2015). The public imagination turned against Chinese communities in 2003, just as it did in the early days of the COVID-19 pandemic.

What's more, Kim also highlights the way that animal activists in particular "mobilized ethnocentric and anti-Chinese feeling among some part of the public" in a string of anti-cruelty campaigns in San Francisco (2015). Though those activists certainly weren't trying to depict Chinese people as backward, callous, or uncivilized, the activists nevertheless did that by singling out practices at Chinese markets instead of far more heinous problems at American factory farms.

\section{Participating in Racist Structures as a Side Constraint}

We haven't told the full story of the economic and cultural importance of wet markets. We obviously haven't given a comprehensive account of pandemics and racist social responses. Still, even this brief sketch should be enough to make it plausible that abolishing wet markets would have significant consequences for many poor people; it also makes it clear that the United States is home to a long and complex history of majority groups linking disease outbreak to the presence of perceived foreigners at home. Importantly, this history includes a trend of blaming foreign food systems for pandemic outbreak, and our contemporary situation is one in which blame on food systems was cast in explicitly racist and xenophobic ways. What's more, while there are plenty of reasons to object to the wildlife trade and the forms of animal agriculture that support wet markets, humans generally cause animals less suffering in those systems than they do in conventional intensive systems. The conclusion of all this seems to be that activists' arguments against wet markets fit into a pattern of targeting and stereotyping institutions that support vulnerable populations. This pattern, we submit, was and is xenophobic, and on top of that, is unlikely to leave animals better off on net. Granted, there may be times and circumstances in which it is appropriate for animal activists to highlight links between COVID-19 and culturally important foodways. At a time of great fear and unrest, however, this involved participating in a xenophobic trend of blaming Chinese culture and citizens for a problem that is obviously caused by a complex set of factors, and which manifested itself in expressions of hatred for, and frustration with, Chinese people generally. So, if activists should avoid taking a non-trivial risk of leaving their beneficiaries seriously worse off due to their efforts when, in running that risk, they would be acting in ways that are morally objectionable for independent reasons, then activists shouldn't have run arguments against wet markets. ${ }^{18}$

\footnotetext{
${ }_{18}$ To be clear, we aren't arguing for a stronger conclusion: namely, that quite apart from the concern we've raised about backfiring, animal activists acted wrongly by failing to resist systemic racism and xenophobia. That could well be true, but it would take more space to establish than we have here.
} 


\section{Conclusion}

We've examined some indirect arguments run by animal activists in the early months of the COVID-19 pandemic. We've argued that the activists who tried to leverage COVID-19 against intensive animal agriculture and wet markets ran the risk of having those arguments backfire. And because some indirect arguments can backfire in more ways than direct onesincluding the ones in question here - making those indirect arguments seems to run afoul of a plausible precautionary principle. What's more, activists who ran arguments against wet market specifically seemed to violate a weaker, and therefore even more plausible, precautionary principle that rules out not running such risks when their actions would be objectionable for independent moral reasons. We conclude, therefore, that there are some important moral considerations against the strategies that these activists pursued.

Our aim, however, is not to take pot shots at people who are trying to make the world better. Rather, we're interested in these cases as a general point of caution against indirect activism that's aimed at reforming the food system for the sake of animals. Our arguments suggest that if activists lobby for animals in ways that don't actually focus on animals, but instead on adjacent issues - such as the threat of future pandemics - they may run significant risks that will be difficult to justify.

Insofar as it's useful for thinking about future strategic choices, what strategies would we have recommended to animal activists in the early months of the pandemic?

In general, we favor avoiding indirect arguments. So, our inclination would be to recommend focusing on tried and true arguments that have animal welfare as their focus. The default, in our view, should be to stay on message. This case serves as a reason why activists should be resistant to going off message by employing indirect strategies.

Granted, it's difficult to get the public to care about nonhuman animals, and so it's natural to want to use other issues as ways of advancing the cause of animals via whatever means available - which will often be an indirect one. Given that this sort of activism is going to happen, we stress the importance of being attentive to the way in which broad coalitions matter in advocacy. This is of special concern for activists' continued public engagement on animals' behalf. Animal advocacy can already be perceived as a cause for affluent, white liberals. And if activists aren't careful, continuing to make sweeping criticisms of institutions that support the poor and members of Chinese society, they run the risk of further cementing an impression of animal advocacy that runs contrary to animals' and activists' interests alike. ${ }^{19}$ It's contrary to activists' interests insofar as it alienates potential allies. And it's contrary to animals' interests insofar as broad coalitions are required to see a major reduction of animal suffering. This doesn't mean that activists are required to be silent about markets that support the wildlife trade. Instead, it's a point in favor of being careful to time and frame challenges in public forums so that they aren't misconstrued and counterproductive.

Additionally, it's a point in favor arguing directly for the reform of wet markets, targeting the way in which live animals are treated and sold, and being careful not to criticize the market itself. Indeed, the zoonotic threat of these markets is related to those stalls that keep, butcher, and sell live terrestrial animals, not the sale of vegetables, fruits, and the many other wares that fill wet market stalls. This also means that it would have been good to avoid the language that has surrounded so many media outlets' discussions of wet markets - language highlighting blood and spillover, feces and guts - which serves to elicit disgust in its readership with little working knowledge of

${ }^{19}$ Thanks to Jacy Reese for raising this point. 
wet markets, but which also mischaracterizes wet markets in general, as many of these are already well-regulated and held to high standards of cleanliness and sanitation. Perhaps most importantly, though, we suspect that it would have been best to advocate directly to those with the power to make reforms - not toward general Western audiences, which are both powerless to elicit the desired change and which are vulnerable to implicit xenophobia.

We understand why activists were quick to try to leverage COVID-19 for their aims. As we've argued, COVID-19 doesn't provide a strong reason to abolish all animal agriculture. Moreover, a pandemic-threat-reducing food system may well end up being bad for the nonhuman animals in it. Additionally, while COVID-19 may well be connected to wet markets, we should be wary of criticizing them given the goal of eradicating racism and xenophobia. We encourage animal activists to think carefully about the pros and cons of indirect arguments on behalf of animals, and in general, to be more critical of their inclination to think that a given crisis can be used to support their preferred changes.

Acknowledgments We received helpful feedback on earlier versions of this paper from Jacy Reese, Nicolas Delon, an audience at the 2020 Philosophy of Activism Workshop, and two anonymous reviewers. We are grateful for their input.

\section{References}

Alexander, Bryan. 2020. Paul McCartney calls on Chinese government to halt 'wet' markets, 'medieval' bat eating. USA Today. https://www.usatoday.com/story/entertainment/music/2020/04/14/paul-mccartneyhoward-sterns-show-calls-end-wet-markets/2993442001/. Accessed April 14, 2020.

Alexandratos, Nikos, and Jelle Bruinsma. 2012. World agriculture towards 2030/2050: The 2012 revision. Food and Agriculture Organization of the United Nations. http://www.fao.org/3/a-ap106e.pdf.

AMR Review. 2015. Antimicrobials in agriculture and the environment: Reducing unnecessary use and waste. The Review on Antimicrobial Resistance. https://amr-review.org/sites/default/files/Antimicrobials\%20in\% 20agriculture $\% 20$ and $\% 20$ the $\% 20$ environment $\% 20-\% 20$ Reducing $\% 20$ unnecessary $\% 20$ use $\% 20$ and $\%$ 20waste.pdf.

Anderson, Jo. 2020. COVID-19 and animals: What the public does and doesn't know. Faunalytics. https:// faunalytics.org/covid-19-poll/. Accessed April 10, 2020.

Aslam, B., W. Wang, M.I. Arshad, M. Khurshid, S. Muzammil, M.H. Rasool, M.A. Nisar, R.F. Alvi, M.A. Aslam, M.U. Qamar, M. Salamat, and Z. Baloch. 2018. Antibiotic resistance: A rundown of a global crisis. Infection and drug resistance 11: 1645-1658. https://doi.org/10.2147/IDR.S173867.

Benatar, David. 2020. Our cruel treatment of animals led to the coronavirus. New York Times. https:/www. nytimes.com/2020/04/13/opinion/animal-cruelty-coronavirus.html. Accessed April 13, 2020.

Bui, Chau Minh, Abrar Ahmad Chughtai, Dillon Charles Adam, and C. Raina MacIntyre. 2017. An overview of the epidemiology and emergence of influenza a infection in humans over time. Archives of Public Health. https://archpublichealth.biomedcentral.com/articles/10.1186/s13690-017-0182-z. Accessed April 10, 2020.

Carrigan, Jo Ann. 1970. Privilege, prejudice, and the Stranger's disease in nineteenth-century New Orleans. The Journal of Southern History 36: 568-578.

CDC. 2019a. Antibiotic / antimicrobial resistance: biggest threats and data. https://www.cdc.gov/drugresistance/ biggest-threats.html. Accessed April 10, 2020.

CDC. 2019b. Camplyobacter. https://www.cdc.gov/campylobacter/index.html. Accessed April 10, 2020.

CDC. 2020. Salmonella. https://www.cdc.gov/salmonella/index.html. Accessed April 10, 2020.

Congress. 2017. H.R.1587 Preservation of antibiotics for medical treatment act of 2017. https://www.congress. gov/bill/115th-congress/house-bill/1587. Accessed April 10, 2020.

Deverell, William. 2004. Whitewashed adobe: The rise of Los Angeles and the remaking of its Mexican past. Berkeley: University of California Press.

Escobar, Natalie. 2020. When xenophobia spreads like a virus. NPR. https://www.npr.org/2020/03/02/ 811363404/when-xenophobia-spreads-like-a-virus. Accessed April 10, 2020. 
Jones, Bryony A., Delia Grace, Richard Kock, Silvia Alonso, Jonathan Rushton, Mohammed Y. Said, Declan McKeever, Florence Mutua, Jarrah Young, John McDermott, and Dirk Udo Pfeiffer. 2013. Zoonosis emergence linked to agricultural intensification and environmental change. Proceedings of the National Academy of Sciences of the United States of America 110: 8399-8404.

Kearney, John. 2010. Food consumption trends and drivers. Philos. Trans. R. Soc. B Biol. Sci 365: $2793-2807$.

Kim, Claire Jean. 2015. Dangerous crossings: Race, species, and nature in a multicultural age. Cambridge: Cambridge University Press.

Haynes, Suyin. 2020. As coronavirus spreads, so does xenophobia and anti-Asian racism. Time. https:/time. com/5797836/coronavirus-racism-stereotypes-attacks/. Accessed April 10, 2020.

Lam, Tommy Tsan-Yuk, Marcus Ho-Hin Shum, Hua-Chen Zhu, Yi-Gang Tong, Xue-Bing Ni, Yun-Shi Liao, Wei Wei, William Yiu-Man Cheung, Wen-Juan Li, Lian-Feng Li, Gabriel M. Leung, Edward C. Holmes, Yan-Ling $\mathrm{Hu}$, and Yi Guan. 2020. Identification of 2019-nCoV related coronaviruses in Malayan pangolins in southern China. BioRXiv. https://doi.org/10.1038/s41586-020-2169-0.

Lindahl, Johanna F., and Delia Grace. 2015. The consequences of human actions on risk for infectious disease: A review. Infection Ecology and Epidemiology 5: 1-11.

Lyall, Jon, Richard M. Irvine, Adrian Sherman, Trevelyan J. McKinley, Alejandro Núñez, Auriol Purdie, Linzy Outtrim, Ian H. Brown, Genevieve Rolleston-Smith, Helen Sang, and Laurence Tiley. 2011. Suppression of avian influenza transmission in genetically modified chickens. Science 331: 223-226. https://doi.org/10. 1126/science. 1198020 .

Mohr, James C. 2005. Plague \& fire: Battling black death and the 1900 burning of Honolulu's Chinatown. New York: Oxford University Press.

Murphy, Macken. 2020. Coronavirus should make you reconsider eating meat. Sentient Media. https:// sentientmedia.org/coronavirus-should-make-you-reconsider-eating-meat/. Accessed April 10, 2020.

Newman, Jonathan, Gary Varner, and Stefan Linquist. 2017. Defending biodiversity: Environmental science and ethics. New York: Cambridge University Press.

Pew Commission on Industrial Farm Animal Production. 2008. Putting meat on the table: Industrial farm animal production in America. Pew Trusts. https://www.pewtrusts.org/-/media/legacy/uploadedfiles/phg/content

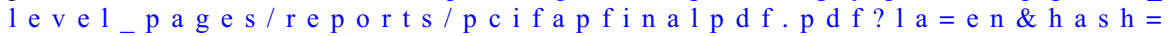
BE87DA9BEE99F8BC836CC7BC841803F73495AFE2. Accessed April 10, 2020.

Shoichet, Catherine E. 2020. What historians hear when Trump calls coronavirus 'Chinese' and 'foreign.' CNN. https:/www.cnn.com/2020/03/12/us/disease-outbreaks-xenophobia-history/index.html. Accessed April 10, 2020.

Singer, Peter, and Paola Cavalieri. 2020. The two dark sides of COVID-19. Project Syndicate. https://www. project-syndicate.org/commentary/wet-markets-breeding-ground-for-new-coronavirus-by-peter-singer-andpaola-cavalieri-2020-03. Accessed April 10, 2020.

Stevens, Matt. 2020. How Asian-American leaders are grappling with xenophobia amid coronavirus. New York Times. https://www.nytimes.com/2020/03/29/us/politics/coronavirus-asian-americans.html. Accessed April $10,2020$.

Stubler, Nico, and Jeff Sebo. 2020. To reduce the risk of pandemics, We Must Ban Factory Farms Now. Sentient Media. https://sentientmedia.org/to-reduce-the-risk-of-pandemics-we-must-ban-factory-farms-now/. Accessed April 10, 2020.

Tomley, Fiona M., and Martin W. Shirley. 2009. Introduction: Livestock infectious diseases and Zoonoses. Philosophical Transactions: Biological Sciences 364: 2637-2642.

Wang, Y., Y. Yang, Y. Shi, H. Song, and C. Yu. 2020. Antibiotic-free antibacterial strategies enabled by Nanomaterials: Progress and perspectives. Advanced Materials 32: 1904106. https://doi.org/10.1002/adma. 201904106.

Warden, Lisa. 2020. Links between COVID-19 and industrial animal farming. Sentient Media. https:// sentientmedia.org/ominous-links-between-covid-19-and-industrial-animal-farming/. Accessed April 10, 2020 .

WWF. 2020. Opinion survey on COVID-19 and wildlife trade in 5 Asian markets: Findings from survey in march 2020. World Wide Fund for Nature.

Xinhua Net. 2020. China focus: Stay away from wild animals, China takes sustained action against illegal wildlife trade. XinhuaNet. http://www.xinhuanet.com/english/2020-02/12/c_138777165.htm. Accessed April 10, 2020.

Zhang, Xianwei, Zicong Li, Huaqiang Yang, Dewu Liu, Gengyuan Cai, Guoling Li, Jianxin Mo, Dehua Wang, Cuili Zhong, Haoqiang Wang, Yue Sun, Junsong Shi, Enqin Zheng, Fanming Meng, Zhang Mao, Xiaoyan He, Rong Zhou, Jian Zhang, Miaorong Huang, Ran Zhang, Ning Li, Mingzhe Fan, Jinzeng Yang, and Wu. Zhenfang. 2018. Novel transgenic pigs with enhanced growth and reduced environmental impact. eLife: 7. https://doi.org/10.7554/eLife.34286. 
Zhong, Shuru, Mike Crang, and Guojun Zeng. 2020. Constructing freshness: The vitality of wet markets in urban China. Agriculture and Human Values 37: 175-185.

Zhong, Taiyang, Zhenzhong Si, Jonathan Crush, Zu Zhiying, Xianjin Huang, Steffanie Scott, Shuangshuang Tang, and Xiang Zhang. 2018. The impact of proximity to wet markets and supermarkets on household dietary diversity in Nanjing City, China. Hungry Cities Partnership 2: 1-17.

Publisher's Note Springer Nature remains neutral with regard to jurisdictional claims in published maps and institutional affiliations.

\title{
Affiliations
}

\section{Alyse Spiehler ${ }^{1} \cdot$ Bob Fischer $^{2}$}

Bob Fischer

fischer@txstate.edu

\author{
UNC Chapel Hill, Chapel Hill, NC, USA
}

2 Texas State University, San Marcos, TX, USA 